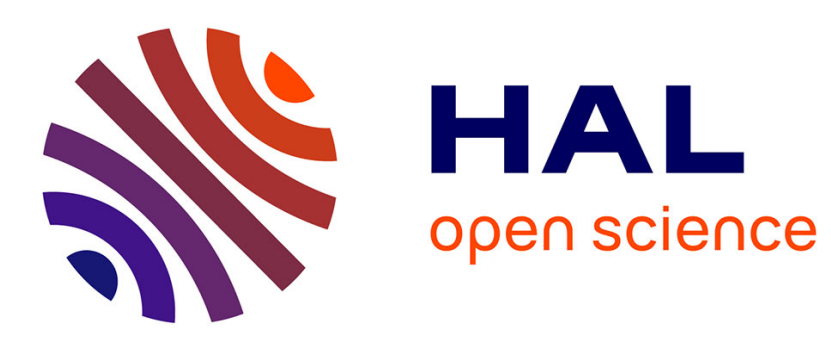

\title{
Ductile to Brittle Transition Fracture Behaviour of Ductile Steel at High Strain Rates
}

\author{
O. Wall, A. Bergmark
}

\section{To cite this version:}

O. Wall, A. Bergmark. Ductile to Brittle Transition Fracture Behaviour of Ductile Steel at High Strain Rates. Journal de Physique IV Proceedings, 1997, 07 (C3), pp.C3-1051-C3-1056. 10.1051/jp4:19973177 . jpa-00255472

\section{HAL Id: jpa-00255472 https://hal.science/jpa-00255472}

Submitted on 1 Jan 1997

HAL is a multi-disciplinary open access archive for the deposit and dissemination of scientific research documents, whether they are published or not. The documents may come from teaching and research institutions in France or abroad, or from public or private research centers.
L'archive ouverte pluridisciplinaire HAL, est destinée au dépôt et à la diffusion de documents scientifiques de niveau recherche, publiés ou non, émanant des établissements d'enseignement et de recherche français ou étrangers, des laboratoires publics ou privés. 


\title{
Ductile to Brittle Transition Fracture Behaviour of Ductile Steel at High Strain Rates
}

\author{
O. Wall and A. Bergmark \\ Department of Solid Mechanics, Lund University, Box 118, 22100 Lund, Sweden
}

\begin{abstract}
The material was a micro alloyed structural steel of three different heat treatment qualities. The micro structure consisted of layers of perlite in a ferrite matrix. The experiments were performed at 30 and $45 \mathrm{~m} / \mathrm{s}$. Depending on load rate the fracture was ductile, brittle or in a mixed mode. Simulations of the experiments showed strain rates of $10^{3}$ to $10^{4}$. At low impact velocity some specimen could withstand the initial load without failing. A maximum likelihood model are used to fit the specimen behaviour to the experimental data.

Résumé: Des spécimens $320 \times 75 \times 18 \mathrm{~mm}$ avec 3 points de flexion étaient soumises à une expérience de impact. Le matériau était en micro allie acier de trois different qualités de traitement de chaleur. Les expériences étaient conduites à 30 et $45 \mathrm{~m} / \mathrm{s}$. Selon la vitesse de la force d' impact, la fracture était ductile, fragile, ou d'une façon intermediaire. Les simulations de les expériences montraient une vitesse de deformation de $10^{3}$ jusqu' à $10^{4}$. À une basse vitesse de l'impact quelque spécimen pouvait supporter la force initiale sans ruine.
\end{abstract}

\section{INTRODUCTION}

The energy required for crack propagation in metals is highly dependent on the fracture mode. The stress state at a crack tip is determined by geometry, loading and loading rate. The maximum strain rate in this investigation is of the order of $10^{4}$. At these high rates of strain the so called ductile steel suffered transition to brittle behaviour, which lead to a lower energy absorption capacity. In order to determine the energy absorption the velocity of the specimen has to be determined in the different phases of loading. The measurement noise in the data makes numerical differentiation impossible. Instead we show how a polynomial regression analyse is used to determine the velocity, and compare it to numerical simulations. We also evaluate the appearance of the fracture surfaces. A thorough analysis, though, of the underlying physical mechanisms and their influence on the constitutive parameters are beyond the scope of this work.

\section{EXPERIMENTAL SETUP}

Experiments have been made on $320 \times 75 \times 18 \mathrm{~mm}$ steel specimens with a fatigue pre cracked quarter notch. The specimen is mounted on an acceleration track sledge and it hits the stationary anvil with a velocity of about 30 or $45 \mathrm{~m} / \mathrm{s}$, fig. 1 . The initial loading on the specimen is obtained from the specimen inertia. If the specimen arrests, a secondary strike at the specimen ends will break it in three point bending, though at lower loading rate. The experiments are monitored by high speed photography operated at $10^{5} \mathrm{fps}$. The relative rotation of the two specimen halves is evaluated from the photos. It is possible to trace the crack growth on the specimen surface. However, a substantial crack growth in the specimen interior precedes the final failure of the surface ligaments. A strain gauge based force transducer is included in the anvil.

For safety reasons the specimen is surrounded by stiff holders, also mounted on the sledge, fig. 1. Five out of seven experiments presented here were run with specimen end constraints which implied a lower 

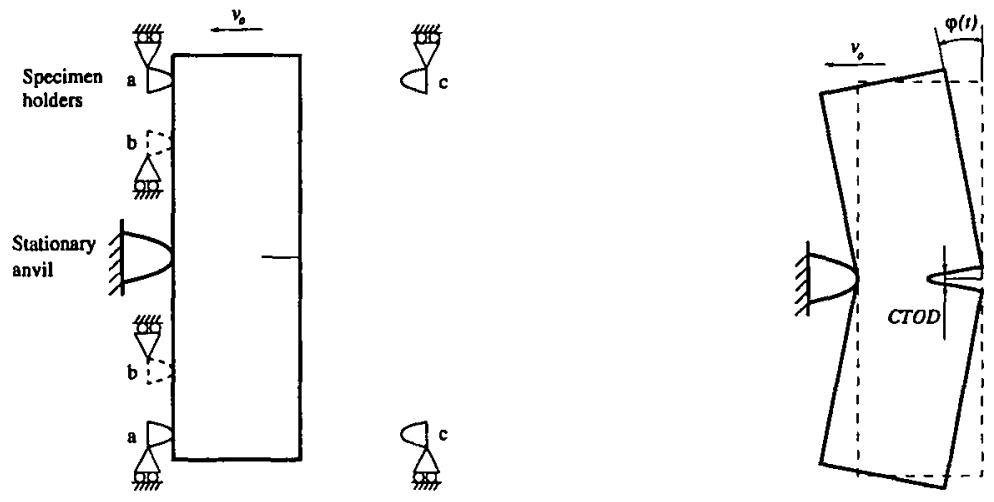

Figure 1: Schematic figure of the specimen with the holder. The specimen runs on a sledge and there are rigid supports attached to the sledge at $a$ and $c$. In the modified design supports were moved from a to $b$.

Figure 2: Loading causing deflection of the specimen halves. $\varphi$ is measured from high speed photos.

rotation rate. The sledge was then modified in order to eliminate the end constraints. Details about the setup are found in Bergmark and Cho [1].

The materials tested were the Swedish micro alloyed structural steels SS 142132 and SS 142134, similar to steel grade E355, quality CC and DD respectively of ISO $4950 / 2$, with a carbon equivalent not exceeding $0.41 \%$. The later, 2134 , is killed and has minimum fracture toughness of $27 \mathrm{~J}$ at standard Charpy-V testing. The steel was received in a controlled rolled condition with a pronounced banded perlitic structure in a ferritic matrix. Sample of the materials can be seen in fig. 3. In 2132, the perlite is found in layers at $30-40 \mu \mathrm{m}$ distance. In the 2134 sample the perlite layers are partly resolved by rolling normalisation. The two materials were tested as delivered, and the later was also tested in a oven normalised condition, $2134 \mathrm{~N}$, with a slightly more heterogeneous material, but the traces of the perlite bands can still be seen.

\section{NUMERICAL SIMULATION}

ABAQUS was used for the numerical simulations of the experiments. A two dimensional model was used with four node elements and about $10^{4}$ dof. Typical element length is $70 \mu \mathrm{m}$ near the crack root. No crack growth was assumed in the simulations. The model was used for both plane stress and plain strain calculations. Strain rate dependent constitutive relations introduced by Perzyna [6] were used,

$$
\dot{\epsilon}_{i j}=\frac{1+\nu}{E} \dot{\sigma}_{i j}-\frac{\nu}{E} \dot{\sigma}_{k k} \delta_{i j}+\beta\langle\phi(f)\rangle \frac{\partial f}{\partial \sigma_{i j}}
$$

where $\nu$ and $E$ are the elastic constants, $\beta$ the fluidity parameter, $\langle\cdot\rangle$ the McCauley bracket and $f\left(\sigma_{i j}, \epsilon_{e f f}^{p}\right)$ is the plastic potential. The flow rate function $\phi(f)$ was taken as

$$
\phi(f)=\left(\frac{\sigma_{e f f}}{\sigma_{y}\left(\epsilon^{p}\right)}-1\right)^{n}
$$

with $\sigma_{e f f}^{2}=\frac{3}{2} s_{k l} s_{k l}$. The values of $\beta$ and $n$ can be obtained by experiments, but in this investigation, as an approximation, we used the values found by Brickstad [2] for a cold rolled steel, $n=2$ and $\beta=4000 \mathrm{~s}^{-1}$. The static strain-stress relation $\sigma_{y}\left(\epsilon^{p}\right)$ was obtained from a uni axial tension test with an initial yield stress of $377 \mathrm{MPa}$, fig. 6 . 


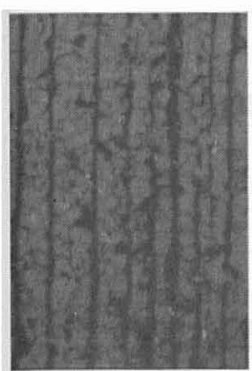

2132

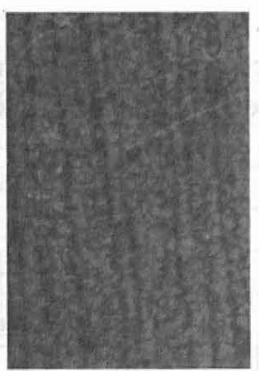

2134

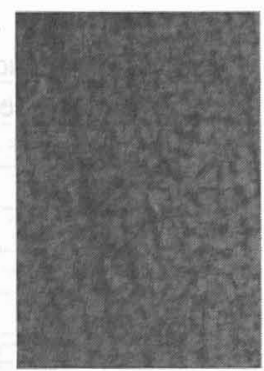

$2134 N$

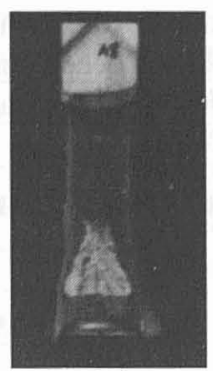

2

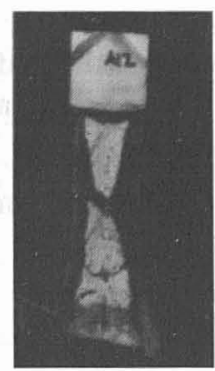

3

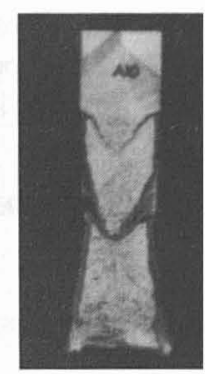

6

Figure 3: The micro structure of 2132, 2134 and $2134 \mathrm{~N}$ perpendicular to the fracture plane and rolling direction. The dark grains are perlite.

Figure 4: The fracture appearances of three different specimens. In table 1 and 2 they correspond to no 2, 3 and 6. The dark areas are ductile fracture and light areas are brittle.

\section{RESULTS}

\subsection{Fractography}

The fracture surfaces were examined visually and by an optical stereo microscope. The first $80 \%$ ( $\approx 45 \mathrm{~mm}$ ) of the surface was classified. The percentage of brittle, flat ductile and slanted fracture were determined, as well as the length of the initial flat ductile fracture and the void size within this zone. Special attention was payed to this zone due to its role at the incipient crack propagation.

The 2134 and $2134 \mathrm{~N}$ material all had traces of ductile fracture at the crack root. At the high loading rate, some of these suffered transition to a brittle mode, and it is most likely that the cleavage started in the specimen interior, linking out to the crack root by a ductile rupture mechanism. The fractographic investigation showed very large voids on the fracture surfaces in this ductile area. Voids with size of 10-20 times the grain size were found. These large voids were a result of high hydrostatic tension. When these large voids linked up, voids of the size of a grain $(\approx 10 \mu \mathrm{m})$ were observed. In the shear lip area there were no macroscopic voids. All voids were on the grain size scale. Even if they are referred to as 'shear lips',

\begin{tabular}{|c|c|c|c|c|c|c|c|c|c|}
\hline \multirow{2}{*}{ No } & \multirow{2}{*}{ Material } & \multirow{2}{*}{$\begin{array}{c}\mathrm{v}_{0} \\
(\mathrm{~m} / \mathrm{s})\end{array}$} & \multirow{2}{*}{$\begin{array}{c}\mathrm{L}_{\text {fatigue }} \\
(\mathrm{mm})\end{array}$} & \multicolumn{3}{|c|}{ Percentage of fracture mode (\%) } & \multirow{2}{*}{$\begin{array}{c}\mathrm{L}_{D I} \\
(\mathrm{~mm})\end{array}$} & \multirow{2}{*}{$\begin{array}{l}\mathrm{D}_{\text {Void }} \\
(\mathrm{mm})\end{array}$} & \multirow{2}{*}{ Label } \\
\hline & & & & Brittle & Flat ductile & Slant ductile & & & \\
\hline 1 & $2134 \mathrm{~N}$ & $30^{*}$ & 23.3 & 0 & 6 & 74 & 3.2 & $1.2^{\dagger}$ & A5 \\
\hline 2 & $2134 \mathrm{~N}$ & $44.6^{*}$ & $\overline{19.8}$ & 17 & 13 & 50 & 1.9 & 0.15 & $\overline{A 8}$ \\
\hline 3 & $2134 \mathrm{~N}$ & 43.1 & 18.1 & 35 & 6 & 39 & 2.9 & 0.15 & $\mathrm{~A} 12$ \\
\hline 4 & 2134 & $30^{*}$ & 18.5 & 9 & 4 & 67 & 1.5 & $0 . \overline{15}$ & A6 \\
\hline 5 & 2134 & $44.4^{*}$ & 20.4 & 31 & 14 & 35 & 1.3 & 0.19 & A7 \\
\hline 6 & 2132 & $28.3^{*}$ & 20.1 & 65 & 0 & 15 & & & $\mathrm{~A} 10$ \\
\hline 7 & 2132 & 30 & 19.5 & 68 & 0 & 12 & & & $\mathrm{~A} 11$ \\
\hline
\end{tabular}

Table 1: Fractographic characterisation of the fracture surfaces. $v_{0}$ is the impact velocity when the specimen hits the anvil. An asterix $(*)$ indicates that the experiment were performed at constrained conditions, see section $2 . L_{f a t i g u e}$ is the length of the pre-fatigue crack. The ductile fractures always initiate by a flat ductile fracture. $L_{D I}$ is the mean length of initial flat ductile area measured from the crack root. There is, though, a large variety of the shape of this zone. $D_{\text {Void }}$ is the mean size of the voids in the initial ductile area. In the first experiment $(\dagger)$, the voids were nucleated by a splitting mechanism between the perlite layers resulting in extremely large voids. 
the straining was directed in the tensile direction.

All 2132 specimen exhibited brittle behaviour with no trace of ductile crack initiation, and thin $(\approx 1 \mathrm{~mm})$ shear lips. For a more in depth analyse of the fracture morphology see Drar and Bergmark [3].

\subsection{Macroscopic specimen behaviour}
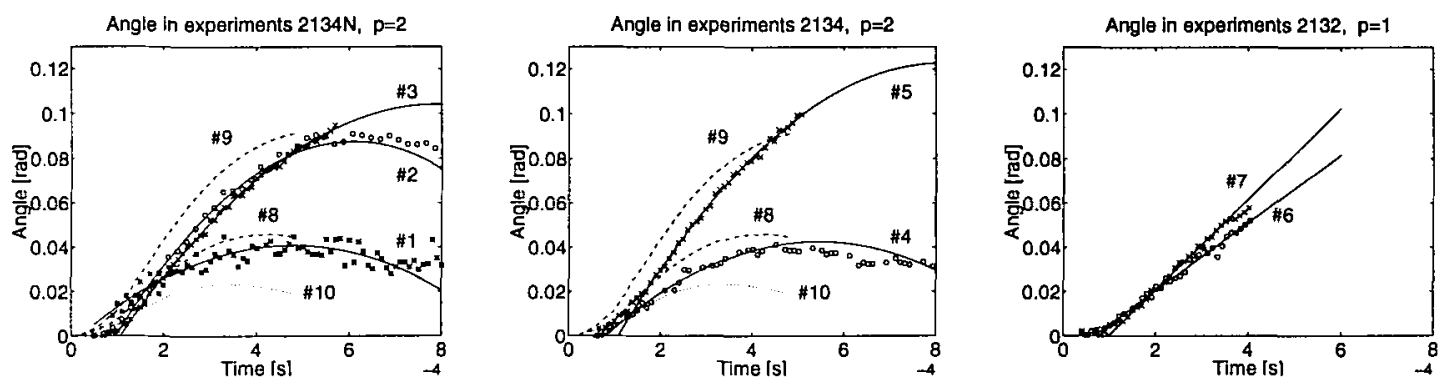

Figure 5: Time versus angle. The solid lines are generated from the regression polynomials where $p$ is the highest power. The marked points are measurements from the experiments, and the dashed and dotted lines are taken from plain stress and plain strain simulations. The \#no refers to the item number in table 1 and 2.

The relative rotation $\varphi(t)$ histories are seen in fig. 5. In order to determine the angular contribution to the kinetic energy, the angular velocity of the specimen halves has to be determined. Numerical differentiation of the data was impossible due to noise in the measurement data. Instead the evaluation were based on a statistical curve fitting. A polynomial regression analysis [4] was based on the model

$$
\varphi(t)=\varphi_{0}+\varphi_{1} t+\varphi_{2} t^{2}+\cdots+\varphi_{p} t^{p}+e(t)=\sum_{k} \varphi_{k} t^{k}+e(t)
$$

where $e(t)$ is an additive normally distributed white noise error with variance $s^{2}$ and $\varphi_{i}$ are the regressors. Note that the model order is $(p+1)$ and the probability density function for the angle $\varphi(t)$ is

$$
f(\varphi(t))=\frac{1}{s \sqrt{2 \pi}} \exp \left(-\frac{1}{2 s^{2}}\left(\varphi(t)-\sum_{k=0}^{k=p} \varphi_{k} t^{k}\right)^{2}\right) .
$$

Values in the time interval $[100,450] \mu$ s were used. Finding the maximum likelihood estimates for $\varphi_{i}$ is equivalent of minimising the function $V\left(\varphi_{i}\right)=\frac{1}{2} \sum_{j=1}^{N} e_{j}^{2}$ for $N$ observations of $\varphi\left(t_{j}\right)$. This is also the leasts squares estimate of the angle. Evaluating the estimated variance and the Akaike Final Prediction Error yields a 1'st order polynomial with a constant angular velocity for the brittle fracture specimens. From the available data it is difficult to predict if a 2'nd or 3'rd order polynomial is appropriate for the ductile specimens based on the FPE. Model order predictions based on FPE are sometimes overestimated so we used a 2'nd order polynomial for describing the angle, with a constant angular acceleration $\alpha$. The mean estimated variance throughout the seven experiment was $s^{2}=0.0029$. The mass moment of inertia was calculated to be approximately $J=0.025 \mathrm{kgm}^{2}$ for each specimen half. The resulting moment is $M=J \alpha$. Three specimen exhibited arrest, see $\varphi_{\text {arr }}$ in table 2 , and were cracked by the second strike by end point loading.

The kinetic energy was calculated before impact, $W_{k}=\frac{m v_{0}^{2}}{2}$, the rotational energy $W_{\omega}=\frac{J \omega^{2}}{2}$ at $t=100 \mu \mathrm{s}$ and $W_{\varphi_{a r r}}=\int_{0}^{\varphi_{a r r}} M d \varphi$ as a measure of the dissipated plastic work in the arrested specimens. 


\begin{tabular}{|c|c|c|c|c|c|c|c|c|c|c|c|}
\hline No & Material & $\begin{array}{c}v_{0} \\
(\mathrm{~m} / \mathrm{s})\end{array}$ & $\varphi_{0}$ & $\varphi_{1}$ & $\varphi_{2}$ & $\begin{array}{l}\alpha \cdot 10^{-3} \\
\left(\mathrm{rad} / \mathrm{s}^{2}\right)\end{array}$ & $\begin{array}{c}\mathrm{M} \\
(\mathrm{Nm})\end{array}$ & $\begin{array}{l}\varphi_{\text {arr }} \\
\text { (rad) }\end{array}$ & $\begin{array}{l}W_{\omega} \\
(J)\end{array}$ & $\begin{array}{c}\mathrm{W}_{\varphi_{\text {art }}} \\
(\mathrm{J})\end{array}$ & $\begin{array}{l}\mathrm{W}_{k} \\
(\mathrm{~J})\end{array}$ \\
\hline 1 & $2134 \mathrm{~N}$ & $30^{*}$ & -0.0036 & 190 & $-200 \cdot 10^{3}$ & -400 & 9900 & 0.041 & 270 & 410 & 890 \\
\hline 2 & $2134 \mathrm{~N}$ & $44.6^{*}$ & -0.036 & 410 & $-330 \cdot 10^{3}$ & -670 & 16700 & 0.088 & 1400 & 1500 & 2000 \\
\hline 3 & $2134 \mathrm{~N}$ & 43.1 & -0.035 & 350 & $-220 \cdot 10^{3}$ & -450 & 11200 & & 1200 & & 1800 \\
\hline 4 & 2134 & $30^{*}$ & -0.016 & 220 & $-200 \cdot 10^{3}$ & -400 & 9900 & 0.043 & 390 & 430 & 890 \\
\hline 5 & 2134 & $44.4^{*}$ & -0.040 & 400 & $-240 \cdot 10^{3}$ & -490 & 12200 & & 1500 & & 1900 \\
\hline 6 & 2132 & $28.3^{*}$ & -0.010 & 150 & & & & & 290 & & 790 \\
\hline 7 & 2132 & 30 & -0.020 & 200 & & & & & 520 & & 890 \\
\hline 8 & P. Stress & 30 & -0.020 & 300 & $-330 \cdot 10^{3}$ & -650 & 16300 & 0.046 & 680 & 750 & 890 \\
\hline 9 & P. Stress & 45 & -0.028 & 420 & $-320 \cdot 10^{3}$ & -630 & 15900 & 0.091 & 1600 & 1400 & 2000 \\
\hline$\overline{10}$ & P. Def. & 30 & -0.0069 & 130 & $-74 \cdot 10^{3}$ & -150 & 3700 & 0.023 & 160 & 90 & 890 \\
\hline
\end{tabular}

Table 2: Result of regression analysis. $\varphi_{0}, \varphi_{1}$, and $\varphi_{2}$ are the regressors and $\alpha, M, \varphi_{\mathrm{arr}}, W_{\omega}, W_{\varphi_{\mathrm{arr}}}$ and $W_{k}$ are physical quantities. All energy quantities relates to a specimen half. Item $8-10$ are results from numerical simulations.

\subsection{Stresses and strains}

From table 2 and fig. 5 it can be seen that the plane stress simulations give a rather fair agreement of the relative rotation between the experiment and the simulations. The calculations give a strain rate perpendicular to the crack plane $1 \mathrm{~mm}$ ahead of the crack tip of $\dot{\epsilon}_{11}=1500, \dot{\epsilon}_{11}=3500$ and $\dot{\epsilon}_{11}=8000$ at 20,30 and $45 \mathrm{~m} / \mathrm{s}$ respectively in the plane stress simulations. In plane deformation, the strain rate is $\dot{\epsilon}_{11}=500$ at $30 \mathrm{~m} / \mathrm{s}$. The histories of logarithmic strain versus stress $1 \mathrm{~mm}$ ahead of the crack tip can be seen in fig. 6 . In the case of plane stress, a high rate of strain increases the yield stress after substantial yielding. For the plane strain case, the strain rate has less influence. Instead the high hydrostatic tension makes the large principal stresses possible.

Narasimhan, Rosakis and Moran [5] simulated crack initiation with both two- and three- dimensional models and showed that plain strain simulations can accurately describe the conditions close to the crack tip in the specimen interior. Their work were though based on static conditions, and the present investigation shows that plain strain simulations can not accurately describe the dynamic macroscopic behaviour, but it is still valuable for estimating the conditions at the crack tip.

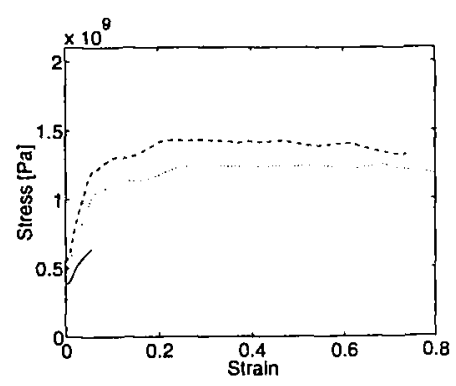

(a) Plain stress, $30 \mathrm{~m} / \mathrm{s}$.

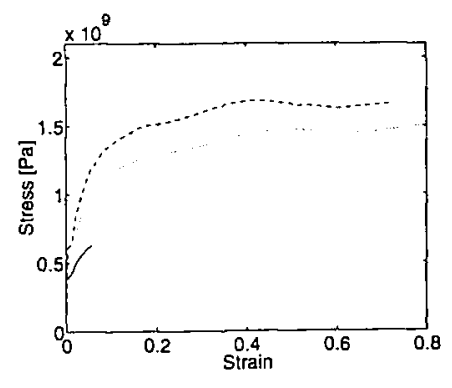

(b) Plain stress, $45 \mathrm{~m} / \mathrm{s}$.

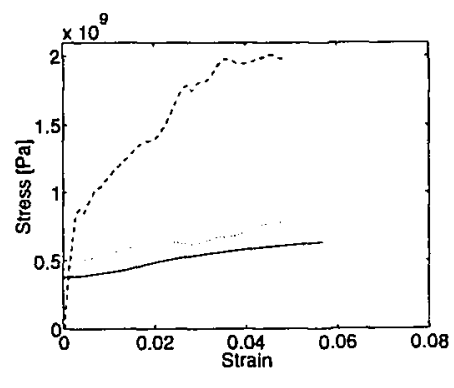

(c) Plain strain, $30 \mathrm{~m} / \mathrm{s}$.

Figure 6: Plots of strain versus stress at $1 \mathrm{~mm}$ ahead of the crack root. The dashed line is a plot of the largest principal log. strain versus principal stress, perpendicular to the crack plane. The dotted line is the effective log. stain versus effective stress and the solid line are data from the experimental static log. plastic strain versus stress. Note the different scale on the abscissa axis in the plane strain plot. 


\section{DISCUSSION}

A simple analysis of angular momentum conservation without any moment acting on a specimen gives angular velocities of 281 and $421 \mathrm{rad} / \mathrm{s}$ at 30 and $45 \mathrm{~m} / \mathrm{s}$ impact velocity respectively. It can be noted that in the *-marked experiments, the resulting moment $M$ is over estimated due to contribution from a force $F$ exerted by the support, see point $a$ in fig. 1. The moment equation is then $J \alpha=M+F l$.

On physical grounds one may argue that the yield stress, and hence the stress state and angular acceleration would be dependent on the angular velocity, implying that a third order polynomial would be appropriate for the regression analysis. However there are other factors such as thermal softening and the anvil stiffness which also will influence the response. The choices of the polynomial degree here rely only on the statistical properties of the measured data. The result of a constant angular velocity for the brittle specimens indicates that the fracture starts early.

Due to the difficulties to determine the fracture starting point, especially for the ductile specimens, and the energy absorption at the impact point, it is hard to make a reliable calculation of the energy absorption capacity of the material with respect to both ductile and brittle fracture. In the *-marked experiments $W_{\varphi_{\text {arr }}}$, like $M$, is over estimated. A more proper energy absorbtion measure in the arrested tests, 1,2 and 4 , is $W_{\omega}$, i.e. the kinetic energy. Material 2134N was tested twice at the high impact velocity, of which one exhibited arrest and the other suffered transition to brittle behavior. The difference in the fracture surface appearence can be seen in fig. 4 , experiment 2 and 3 .

\section{References}

[1] Bergmark A and Cho J.U. Dynamic crack propagation in 3PB ductile steel specimens. Technical report, Dept. of Solid Mechanics, Lund University, 1991.

[2] Brickstad B. A viscoplasic analysis of rapid crack propagation experiments in steel. Journal of the Mechanics and Physics of Solids, 31(4):307-327, 1983.

[3] Drar $\mathrm{H}$ and Bergmark A. Load rate influence on the fracture morphology of a ductile steel. Engineering Fracture Mechanics, 46(2):225-233, 1993.

[4] Johansson R. System Modelling and Identification. Prentice Hall, New York, 1993.

[5] Narasimhan R, Rosakis A.J, and Moran B. A three-dimensional investigation of fracture initiation by ductile failure mechanisms in 4340 steel. International Journal of Fracture, 56:1-24, 1992.

[6] Perzyna P. Fundamental problems in viscoplasticity. Advances in Applied Mechanics, 9:243-377, 1966. 